\title{
Message from the Chief Editor
}

\author{
Tetsuo Gotoh
}

Published online: 22 January 2015

(C) The Japanese Society of Applied Entomology and Zoology 2015

The board of the Japanese Society of Applied Entomology and Zoology has invited me to continue as Chief Editor of Applied Entomology and Zoology, the official Englishlanguage journal of the Society, for the period 2015-2016, and I have gratefully accepted. My most important duty as Chief Editor is to safeguard the scientific quality of the journal. The scope of Applied Entomology and Zoology is extremely diverse; it includes ecology, environmental science, ethology, molecular biology, physiology, taxonomy, and toxicology, and covers both pest and beneficial insects and other animals. Studies that identify chemical components with insecticidal activity in plant extracts also fall within our scope. Unfortunately, we cannot cover fisheries science or veterinary pests other than arthropods. We welcome submission of primary research papers and literature review articles. I feel responsible for the continuation of Applied Entomology and Zoology as a leading journal covering these scientific topics. Given its broad scope, however, it goes without saying that I can do this only with the help of the associate editors, Drs Tetsuya Kobayashi, Katsuyuki Kohno, Shiro Nakao, Haruki Tatsuta, Makoto Tokuda, and Hiroe Yasui, and the Editorial Board.

Since 2011 the Japanese Society of Applied Entomology and Zoology has published Applied Entomology and
Zoology with Springer. Publication with Springer has made access from other countries easier; the number of submissions in 2014 was $40 \%$ higher than in 2011, and the number of manuscripts rejected has increased to ca $70 \%$. The journal's impact factor increased to 0.877 in 2013. To keep up with the increasing number of papers submitted, and to increase the quality of the papers published and the status of the journal, I decided to increase the number of associate editors to six (four in the period 2013-2014). The Editorial Board now consists of 76 members, 16 of whom (21\%) are researchers outside Japan. In addition to the Board members, 27 overseas' researchers also acted as peer reviewers in 2014. Together we managed to shorten the time from manuscript submission to first decision from 44.5 days in 2011 to 28.2 days in 2014. Because of all these recent developments, I am optimistic that the improvement in the quality of the journal will continue.

\section{Tetsuo Gotoh Chief Editor \\ Applied Entomology and Zoology}

T. Gotoh $(\bowtie)$

Ibaraki University, Ami, Ibaraki 300-0393, Japan

e-mail: gotoh@odokon.org 